\title{
Column Formation in Suspension Plasma-Sprayed Coatings and Resultant Thermal Properties
}

\author{
Kent VanEvery, Matthew J.M. Krane, Rodney W. Trice, Hsin Wang, Wallace Porter, Matthew Besser, \\ Daniel Sordelet, Jan Ilavsky, and Jonathan Almer
}

(Submitted November 15, 2010; in revised form February 15, 2011)

\begin{abstract}
The suspension plasma spray (SPS) process was used to produce coatings from yttria-stabilized zirconia (YSZ) powders with median diameters of $15 \mu \mathrm{m}$ and $80 \mathrm{~nm}$. The powder-ethanol suspensions made with 15- $\mu \mathrm{m}$ diameter YSZ particles formed coatings with microstructures typical of the air plasma spray (APS) process, while suspensions made with 80 -nm diameter YSZ powder yielded a coarse columnar microstructure not observed in APS coatings. To explain the formation mechanisms of these different microstructures, a hypothesis is presented which relates the dependence of YSZ droplet flight paths on droplet diameter to variations in deposition behavior. The thermal conductivity $\left(k_{t h}\right)$ of columnar SPS coatings was measured as a function of temperature in the as-sprayed condition and after a $50 \mathrm{~h}, 1200{ }^{\circ} \mathrm{C}$ heat treatment. Coatings produced from suspensions containing $80 \mathrm{~nm}$ YSZ particles at powder concentrations of 2,8 , and 11 wt. $\%$ exhibited significantly different $k_{\text {th }}$ values. These differences are connected to microstructural variations between the SPS coatings produced by the three suspension formulations. Heat treatment increased the $k_{\text {th }}$ of the coatings generated from suspensions containing 2 and 11 wt. $\%$ of $80 \mathrm{~nm}$ YSZ powder, but this $k_{\text {th }}$ increase was less than has been observed in APS coatings.
\end{abstract}

Keywords APS coatings, PS microstructures, suspension plasma spray, thermal properties

\section{Introduction}

Yttria-stabilized zirconia (YSZ) coatings are widely used in gas turbines to insulate metallic components from the heat generated during engine operation (Ref 1$)$. These thermal barrier coatings (TBCs) are commonly applied through either the electron beam physical vapor deposition (EB-PVD) or air plasma spray (APS) processes (Ref 1,2$)$. In the case of EB-PVD, electron beam heating of a YSZ ingot produces a vapor that subsequently condenses on the substrate (Ref 1,2). In APS, YSZ powder is injected into a DC plasma which melts the powder particles while propelling them onto the substrate (Ref 1-3). The differences in the two processes lead to distinct coating microstructures (Ref 4-7).

Kent VanEvery, Progressive Surface, Grand Rapids, MI; Matthew J.M. Krane and Rodney W. Trice, School of Materials Engineering, Purdue University, West Lafayette, IN; Hsin Wang and Wallace Porter, Oak Ridge National Laboratory, Oak Ridge, TN; Matthew Besser, Ames Laboratory, Ames, IA; Daniel Sordelet, Caterpillar, Peoria, IL; and Jan Ilavsky and Jonathan Almer, Argonne National Laboratory, Argonne, IL. Contact e-mail: rtrice@purdue.edu.
An EB-PVD YSZ coating consists of a collection of columnar, quasi-single crystals (Ref 6, 7). Typical deposition conditions result in these crystals growing primarily normal to the substrate surface, which is located directly above the flux emitted by the vaporized feedstock (Ref 8 , 9). The resulting columnar grains, which tend to extend from the substrate to the coating top surface, usually have diameters on the order of $10 \mu \mathrm{m}$ (Ref 6,7 ). These grains contain closed and open pores and are separated from neighboring columns by a continuous gap that varies in width from a few nanometers at the substrate to $\sim 1 \mu \mathrm{m}$ near the coating top surface (Ref 6,7).

An APS coating is deposited by liquid droplets that impact a substrate, spread across the surface, and solidify into disc-like structures referred to as lamellae (Ref 3, 4, 10). During droplet spreading the liquid may not completely wet the underlying surface, which will result in interlamellar pores (Ref 3,4). Despite the presence of these interlamellar pores, heat is transferred out of a spread droplet mainly through the boundary in contact with the substrate or previously deposited coating (Ref 4, 11, 12). Consequently, as a lamella solidifies, columnar grains grow perpendicular to this boundary (Ref 10-12). The contraction accompanying lamella solidification and cooling generates strains that can form cracks (Ref 4, 11, 12). Since the bonding within grains is stronger than between them, these intralamellar cracks tend to propagate along the grain boundaries, cutting the lamella. An APS YSZ coating is thus composed of lamellae, interlamellar porosity mainly oriented with radial axes parallel to the substrate, and intralamellar cracks aligned normal to the 
substrate (Ref 4, 10,12). In the literature cited above, the APS microstructure is frequently presented as an archetype describing all coatings produced by using a plasma to melt and deposit YSZ powder; however, as will be presented here, such a description may not apply to the coatings resulting from plasma spraying YSZ powders with single digit micron and smaller diameters.

In APS, the feedstock particles are introduced into the plasma by a carrier gas (Ref 3$)$. As the particle diameters decrease, the carrier gas flow rate must increase in order to inject the less massive particles into the plasma plume (Ref 3). For most powder materials, the injection of particles with diameters $<5 \mu \mathrm{m}$ requires carrier gas velocities that significantly perturb the plasma flow, reducing the overall deposition efficiency (Ref 3). In addition, the electrostatic surface forces between micron-sized and smaller particles can dominate the gravitational body forces acting on the particles, resulting in particle agglomeration and an inability to feed material through the powder supply line (Ref 13). In many cases, the technical issues associated with spraying micron and submicron diameter powders (i.e., increased carrier gas flow and feedstock agglomeration) can be solved by spraying suspensions (Ref 13,14). Compared to a gas carrier, the more massive liquid carrier can generate the momentum required to inject these small powders into the plasma stream at velocities that do not negatively impact the coating process. Furthermore, a liquid carrier can contain dispersants that inhibit powder agglomeration (Ref 3, 13, 15). These advantages have led to the development of the suspension plasma spray (SPS) technique (Ref 13, 14, 1619).

In SPS, the suspension is typically injected into the plasma plume through a nozzle that produces a coherent suspension stream or a stream of suspension droplets (Ref 17, 19). Aerodynamic drag forces from the plasma flow cause the initial stream or droplets to fragment into smaller, stable droplet sizes (Ref 15, 17). The droplet size is decreased further as the solvent evaporates (Ref 13, 15, 17). To reduce the enthalpy required for vaporization, a volatile liquid like ethanol is commonly used for the suspension solvent (Ref 13, 15). Under optimal deposition conditions, the solvent in the droplet fully evaporates, leaving individual powder particles or agglomerates that melt prior to impacting on the substrate (Ref 13, 20). Achieving these conditions with the micron and submicron droplets generated in SPS requires the use of shorter standoff distances between the plasma torch exit and the substrate than is typical for APS (Ref 20). This reduction is necessary to decrease the occurrence of droplet solidification prior to deposition. A shorter standoff distance results in the substrate experiencing a greater heat flux. As a result, SPS usually involves more substrate cooling than is used in APS to prevent thermal stress generation within a coating from causing spallation (Ref 13).

The microstructure of plasma-sprayed coatings can change as the feedstock powder size is reduced. For example, decreasing the average powder diameter can increase the velocity of depositing droplets, which yields thinner lamellae (Ref 12 ). Thus, with the ability to spray submicron feedstocks, the SPS process has the potential to generate coatings in which the density of interlamellar pores is significantly larger than what is common in APS coatings. Such a change is likely to affect the coating thermal conductivity. At $1250{ }^{\circ} \mathrm{C}$, which is close to the maximum gas temperature at the inlet of a commercial aircraft turbine engine, photon transport comprises $10 \%$ of the total heat flux through a 6-8 wt.\% YSZ ceramic (Ref 21, 22). Therefore, the majority of the heat transfer through the YSZ TBCs in aircraft engines occurs by phonon transport in the ceramic lattice. Increasing the density of interlamellar pores should cause these phonons to follow more tortuous paths through the microstructure, which would lower the coating thermal conductivity (Ref 23). Consequently, SPS could provide a means of improving the insulating performance of TBCs relative to current APS thermal barriers. The current study was undertaken to evaluate this possibility by characterizing the microstructure and thermal conductivity of YSZ coatings produced from nanoscale powder feedstock.

\section{Experimental Procedures}

\subsection{Coating Production}

SPS was employed to generate coatings from suspensions of two different sized YSZ powders in ethanol. The particle size distributions within all of the suspensions employed in this study were measured with a Beckman Coulter $^{\circledR}$ (Fullerton, CA) LS 230 particle size analyzer (Ref 24). A density of $6.0 \mathrm{~g} / \mathrm{cm}^{3}$ and complex refractive index of 2.16-0.01i were used for powder size calculations (Ref 24-27).

Micron feedstock suspensions were produced with a $\mathrm{ZrO}_{2}-7$ wt. $\% \mathrm{Y}_{2} \mathrm{O}_{3}$ fused and crushed powder from H.C. Starck, Inc (Euclid, OH) as described in Table 1. No ball milling was performed on this type of suspension. The coatings produced from the $15-\mu \mathrm{m}$ diameter YSZ suspensions will subsequently be referred to as $8 \mathrm{M}$ coatings, where the number represents the powder loading in wt.\% and the letter represents the powder size, in this case, micron-sized powders.

The nanofeedstock suspensions contained $\mathrm{ZrO}_{2-}$ 8 wt. $\% \mathrm{Y}_{2} \mathrm{O}_{3}$ powder synthesized by Inframat ${ }^{\circledR}$ Advanced Materials (Manchester, CT). Nanoparticle suspensions were formulated as detailed in Table 1; the resulting

Table 1 Suspension formulation details

\begin{tabular}{|c|c|c|c|}
\hline Suspension & $\begin{array}{l}\text { Powder } \\
\text { conc., wt. } \%\end{array}$ & Solvent $^{\mathbf{a}}$ & YSZ particulate $d_{50}$ \\
\hline $8 \mathrm{M}$ & 8 & Ethanol & $15 \pm 6 \mu \mathrm{m}$ (volume-based) \\
\hline $2 \mathrm{~N}$ & 2 & Ethanol & $85 \pm 13 \mathrm{~nm}$ (number-based) \\
\hline $8 \mathrm{~N}$ & 8 & Ethanol & $85 \pm 13 \mathrm{~nm}$ (number-based) \\
\hline $11 \mathrm{~N}$ & 11 & Ethanol & $89 \pm 13 \mathrm{~nm}$ (number-based) \\
\hline \multicolumn{4}{|c|}{$\begin{array}{l}{ }^{\text {a }} \text { Contained } 1 \text { wt. \% phosphate ester dispersant (Triton }{ }^{\circledR} \text { QS-44 from } \\
\text { Sigma-Aldrich }{ }^{\circledR} ; \text { St. Louis, MO) }\end{array}$} \\
\hline
\end{tabular}


coatings will be referred to here as 2,8 , and $11 \mathrm{~N}$ coatings, respectively, where " $\mathrm{N}$ " stands for nanoparticle. After formulation the suspensions were milled for $3 \mathrm{~h}$ on a rolling jar mill; the grinding media employed for this process were $9.5-\mathrm{mm}$ diameter by $9.5 \mathrm{~mm}$-long cylinders of dense YSZ. Following milling no statistical difference existed between the number-based $d_{50}$ particle size for 2 , 8 , and $11 \mathrm{~N}$ suspensions.

Coatings were fabricated at Ames Laboratory (Ames, IA) by spraying directly on 24-grit alumina-blasted copper substrates that were $2.5-\mathrm{cm}$ wide $\times 10-\mathrm{cm}$ long $\times 0.5-\mathrm{cm}$ thick. Suspensions were agitated prior to and during the spray process using a combination of manual mixing, ultrasonics, and a magnetically driven stir bar. Furthermore, all suspensions were filtered through a $90 \mu \mathrm{m}$ sieve, while being added to the pressure vessel used to supply the suspension to the plasma torch.

The experimental conditions briefly reviewed below were determined from a parametric study of the SPS process employed for this work and were found to minimize the volume fraction of unmelted YSZ powder observed within the coatings (Ref 28, 29). The plasma torch was a Praxair (Indianapolis, IN) SG-100 configured with a 3083-129 cathode, 3083-175 anode, 3083-113 gas injector, and a 6-mm diameter nozzle. The torch was operated at a current of $1000 \mathrm{~A}$ with primary and secondary plasma forming gas flows of $20 \mathrm{slpm} \mathrm{Ar}$ and $60 \mathrm{slpm} \mathrm{He}$, respectively, which produced a gun voltage of $50 \mathrm{~V}$. The spray direction describing the plasma flow exiting the gun was perpendicular to the grit-blasted surface. During deposition, the torch rastered horizontally at $29 \mathrm{~cm} / \mathrm{s}$ across this substrate surface; consecutive passes were separated by $3 \mathrm{~mm}$. The backside of the substrate was cooled using air jets with a combined volumetric flow rate of roughly $2700 \mathrm{lpm}$. A steel shroud surrounding the substrate prevented the cooling air from interacting with the depositing YSZ droplets. The substrate temperature was not monitored during spraying.

Table 2 lists the spray parameters for the SPS experiments conducted during this study. All suspensions were injected as coherent streams orthogonal to the plasma flow. These streams were generated by using nitrogen gas to force the suspension within a pressure vessel through plastic tubing connected to a $230-\mu \mathrm{m}$ diameter ruby orifice. This orifice was purchased from Bird Precision (Waltham, MA) and mounted on the internal injection port of the anode body. The minimum final coating thickness desired in all experiments was $300 \mu \mathrm{m}$.

Table 2 Experimental spray parameters

\begin{tabular}{lrrrr}
\hline Suspension & $\mathbf{8}$ M & $\mathbf{2 ~ N}$ & $\mathbf{8 ~ N}$ & $\mathbf{1 1} \mathbf{~ N}$ \\
\hline Standoff, cm & 10 & 5 & 5 & 5 \\
Injection pressure, MPa & 29 & 45 & 45 & 45 \\
Suspension flow, $\mathrm{mL} / \mathrm{min}$ & 42 & 52 & 52 & 52 \\
Coating thickness, $\mu \mathrm{m} /$ pass & 4 & 1 & 6 & 6 \\
\hline
\end{tabular}

\subsection{Thermal Conductivity Measurement}

Thermal diffusivity values were determined for 2,8 , and $11 \mathrm{~N}$ coatings. These measurements were conducted using the laser flash system located at the High Temperature Materials Laboratory on the Oak Ridge National Laboratory (Oak Ridge, TN) campus. Test specimens consisting of $12.7-\mathrm{mm}$ diameter discs were cut into SPS coatings and removed from the substrate by dissolving the copper in nitric acid. Before testing, these specimens were coated with graphite because of the YSZ transparency to the laser radiation. The test specimens were oriented such that the effective direction of heat transfer through the microstructure was parallel to the coating spray direction. The diffusivity values calculated from the temperature change were converted to conductivities using YSZ specific heat data and the bulk density of each sample. Bulk density and total porosity was measured via an Archimedes approach. Additional details about this process have been published previously (Ref 28).

\subsection{Small Angle Scattering Experiments}

Small angle $\mathrm{x}$-ray scattering (SAXS) experiments were performed on 2 and $8 \mathrm{~N}$ coating samples at the Advanced Photon Source facility within Argonne National Laboratory (Argonne, IL) to characterize the void surfaces within these microstructures. Because of the high demand for the beamline needed to generate SAXS data, a second round of experiments could not be conducted to characterize $8 \mathrm{M}$ and $11 \mathrm{~N}$ microstructures. The samples investigated were obtained by using a robotic diamond saw to cut 1$\mathrm{mm}$ wide sections along the $12.7-\mathrm{mm}$ diameter of the disc specimens evaluated in the laser flash diffusivity testing. Each section was epoxyed to a bolt so that it could be attached to an electromechanical positioning system and placed into a $100-\mu \mathrm{m}$ wide by $30-\mu \mathrm{m}$ tall beam of collimated, monochromatic x-rays. In these experiments, the beam was directed onto a coating sample along a path that was perpendicular to the spray direction. Comparing the signal strength detected before and after the coating section permitted the determination of sample positions that resulted in the beam passing through the coating section. By manipulating the sample position, SAXS data were recorded from a series of adjacent coating volume segments; for each of the samples tested, the total coating volume evaluated was roughly $500 \times 350 \times 1000 \mu \mathrm{m}$.

As the $\mathrm{x}$-rays passed through a sample, differences in the electron densities at the interfaces between the ceramic and the gas within cracks and pores coherently scattered waves along small angles from the beam direction (Ref 30). Some of these waves did not undergo any further scattering, and, as a result, the associated intensities were correlated via a Porod constant to the total void specific surface area (SSA) within the beam interaction volume (Ref 5,31 ). In addition, by recording the scattered intensities with a two-dimensional detector, the void SSA variation in directions perpendicular to the beam was plotted from the intensities of the singly scattered waves. The direction of each of these scattering events was perpendicular to the void surface (Ref 31,32 ). Therefore, the

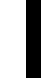


data in a given direction on the 2-D intensity plot was the result of voids aligned along an orthogonal direction.

For each 2 and $8 \mathrm{~N}$ sample, scattering data was collected from only one sample orientation because plasmasprayed coatings demonstrate rotational symmetry along a spray direction perpendicular to the substrate (Ref 31). As a result, orienting each sample so that the incident beam was normal to the spray direction yielded results which could be rotated to form a complete description of scattering from the entire the sample void system (Ref 31). However, because they were not confirmed by conducting scattering experiments at multiple sample orientations, the term apparent is applied to the void SSA results for the 2 and $8 \mathrm{~N}$ samples per the convention of Ilavsky et al. (Ref 31). A further description of the setup and conditions for these experiments has been published elsewhere (Ref 28).

\section{Results}

\subsection{Microstructural Description}

Figure 1 shows that the $8 \mathrm{M}$ coating microstructures were the same as those of a typical APS coating, consisting of overlapping lamellae that were $\sim 10 \mu \mathrm{m}$ and larger (i.e., longer than the image width) in diameter and several microns thick. Lamellae often contained multiple intralamellar cracks (Fig. 1a), and interlamellar pores were observed between lamellae (Fig. 1b). Given the similarity to APS microstructures, solvent evaporation during the $8 \mathrm{M}$ experiments does not appear to have affected the coating microstructure morphology.

As shown in Fig. 2, the SPS coatings produced from nanopowder suspensions were also composed of lamellae. These lamellae were significantly smaller than those in the $8 \mathrm{M}$ coatings, having single digit micron diameters and thicknesses in the hundreds of nanometers. Among the nanopowder feedstock coatings, the lamella diameters appeared to increase with suspension powder concentration. For example, the $11 \mathrm{~N}$ microstructure in Fig. 2(c) exhibits lamellae with larger diameters than those shown in the $8 \mathrm{~N}$ microstructure of Fig. 2(a). As the particle size measurements showed the nanopowder suspensions to have equivalent $d_{50}$ values, a difference in lamella size is likely due to powder concentration differences in the fragmented suspension droplets within the plume. The evaporation/combustion of the solvent in these droplets will eventually cause the powders to touch (Ref 13, 33). On complete melting, the resulting powder agglomerate will form one droplet. Agglomerates composed of an increased volume of powders, as would be the case for $11 \mathrm{~N}$ suspensions compared to $8 \mathrm{~N}$ suspensions, should lead to larger droplets. Thus, the suspension powder concentration in SPS can influence the size of coating microstructural features in a manner analogous to the powder feedstock diameter in APS (Ref 34).

Lamellar pores still existed between lamellae in the 2 , 8 , and $11 \mathrm{~N}$ coatings, an example of which can be seen in Fig. 2(b). However, unlike the $8 \mathrm{M}$ coatings, the majority
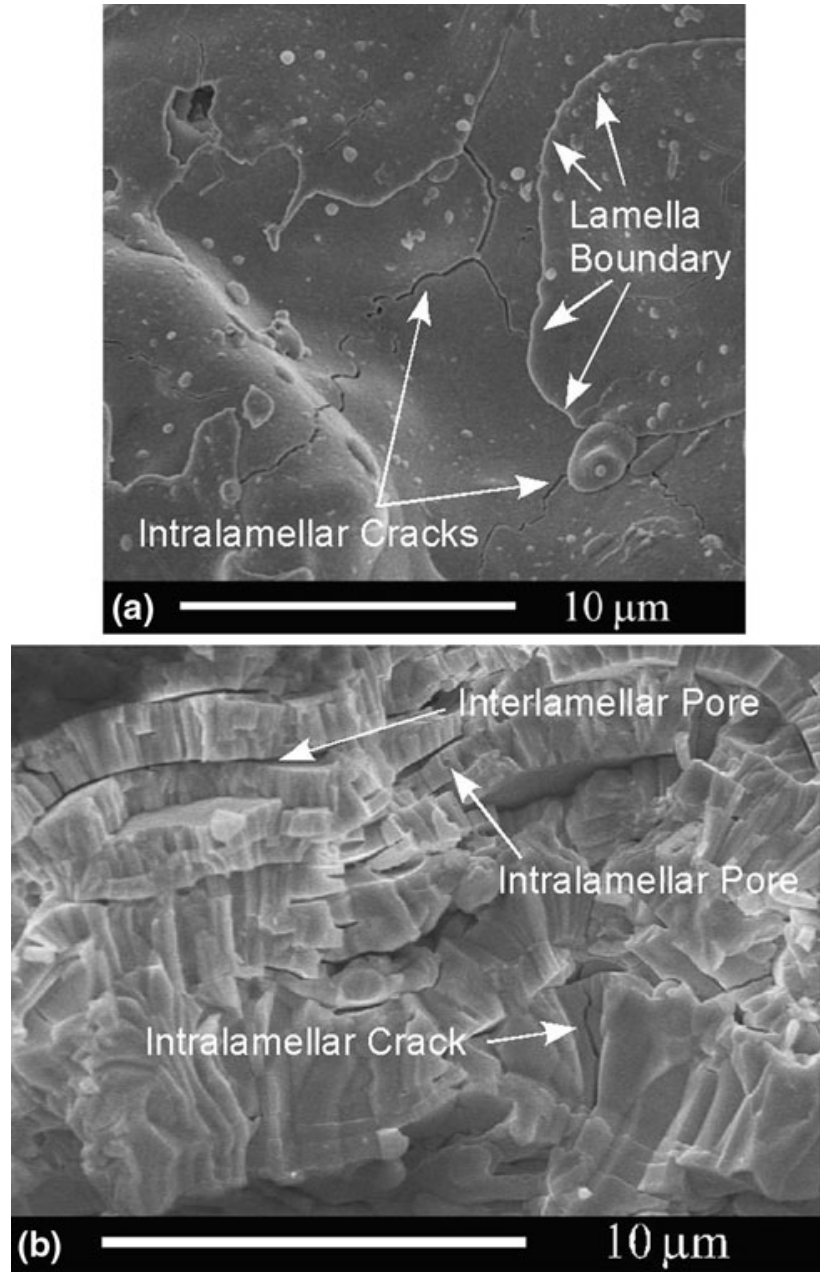

Fig. 1 SEM images from an $8 \mathrm{M}$ coating showing (a) a high magnification of the top surface and (b) a fractured cross section normal to the substrate

of lamellae visible in micrographs of the $2 \mathrm{~N}$ (not shown), $8 \mathrm{~N}$ (Fig. 2a), and $11 \mathrm{~N}$ (Fig. 2c) top surfaces did not contain cracks. In fact, intralamellar cracking was only observed among the largest YSZ lamellae within the 8 and $11 \mathrm{~N}$ microstructures. The difference in the contraction along the lower and upper surfaces during cooling will increase with the lamella thickness. Consequently, in comparison to the $8 \mathrm{M}$ lamellae, smaller strains were generated within the thinner diameter 2,8 , and $11 \mathrm{~N}$ lamellae, which decreased intralamellar cracking in these microstructures.

As shown in Fig. 3 and 4, the differences between nanometer and micrometer feedstock fabricated coatings went beyond lamella dimensions and cracking. Cauliflower-like cluster formations comprised the top surfaces of the $2 \mathrm{~N}$ (Fig. 3a), $8 \mathrm{~N}$ (Fig. 3b), and $11 \mathrm{~N}$ (Fig. 3c) coatings, although the cluster formations are noticeably less distinct on the top surface of $11 \mathrm{~N}$ coatings than on those of the 2 or $8 \mathrm{~N}$ coatings. Cross-sectional microstructures exhibited bands of porosity which resulted in columnar YSZ structures with diameters of $\sim 100 \mu \mathrm{m}$ 

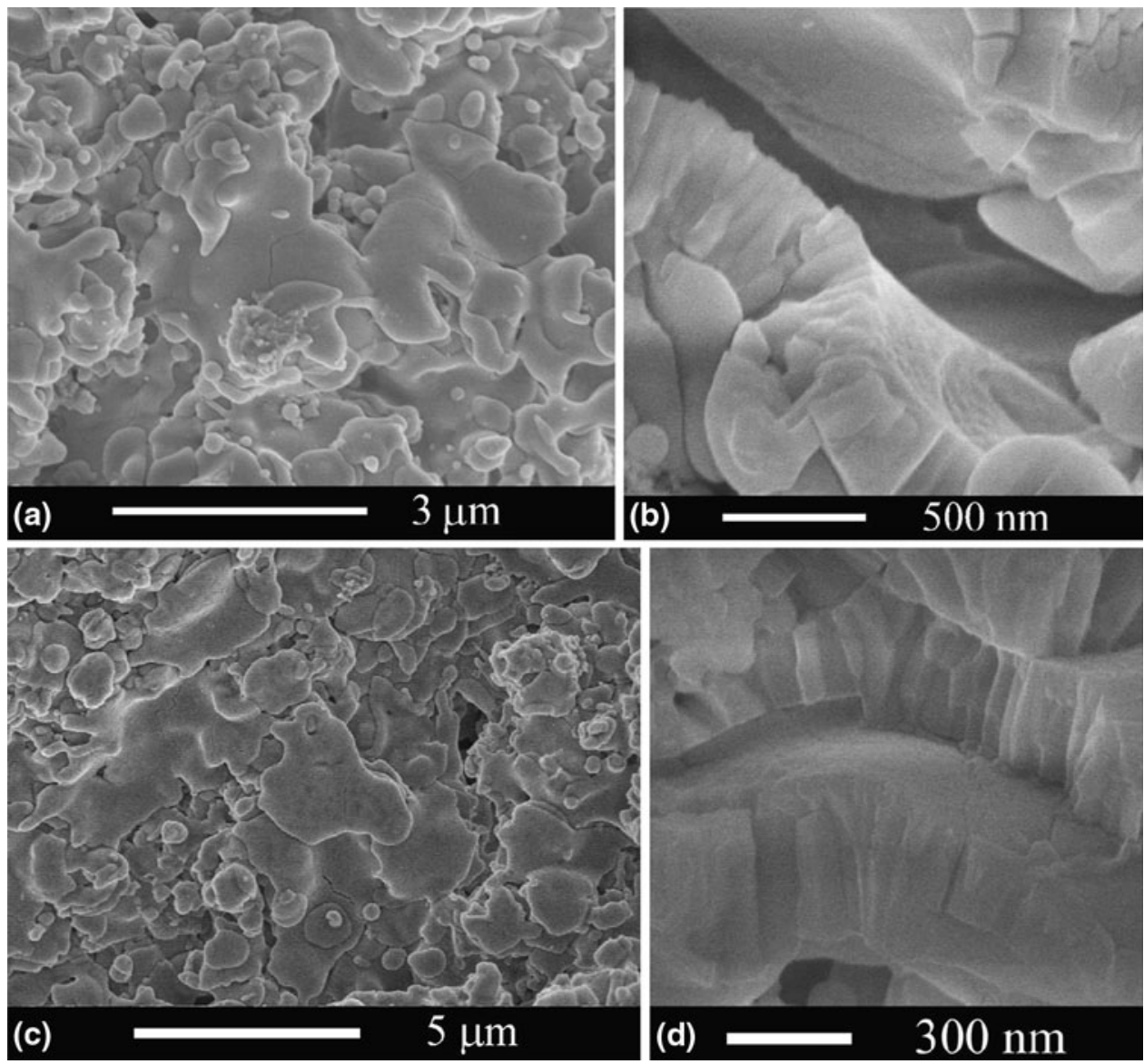

Fig. 2 SEM images showing (a) the top surfaces of $8 \mathrm{~N}$ lamellae, (b) a lamellar pore between $8 \mathrm{~N}$ lamellae, (c) the top surfaces of $11 \mathrm{~N}$ lamellae, and (d) cross sections of fractured $8 \mathrm{~N}$ lamellae

(Fig. 4a). In the 2 and $8 \mathrm{~N}$ coatings, as shown in Fig. 4(b) and (c), the columns tended to extend through the coating thickness. The cross-sectional microstructure of the $11 \mathrm{~N}$ coating was subtly different from those of the 2 and $8 \mathrm{~N}$ coatings in that the $11 \mathrm{~N}$ porosity bands tended to merge (Fig. 4d). This change resulted in fewer columnar structures spanning the thickness of the $11 \mathrm{~N}$ coatings.

\subsection{Small Angle Scattering Results}

Figure 5 is the SAXS data for an as-sprayed (AS) $8 \mathrm{~N}$ coating. The near circular azimuthal dependence of the Porod constants calculated from the singly scattered x-ray intensities is representative of SAXS data obtained for the AS $2 \mathrm{~N}$ coatings previously published (Ref 28 ), and 2 and $8 \mathrm{~N}$ coatings after heat-treatment (not shown) (Ref 28, 29). This result indicates that the combined apparent SSA of cracks and pores within these coatings was approximately isotropic. In addition, the SAXS results showed that the total apparent void SSA decreased by $\sim 30 \%$ after $50 \mathrm{~h}$ at $1200{ }^{\circ} \mathrm{C}$, suggesting sintering occurred during the heat treatment (Ref 29).

SAXS experiments were not conducted on $8 \mathrm{M}$ coating samples. However, small angle neutron scattering (SANS) investigations (Ref 5, 31, 32) have previously examined the void SSA orientation in APS YSZ coatings produced with a spray direction orthogonal to the substrate surface. The reported findings should be applicable to the $8 \mathrm{M}$ coatings in the current research. In fact, the work by Petorak (Ref 32) used the same powder as that employed to produce the $8 \mathrm{M}$ coatings. The SANS data in these studies show the APS YSZ coating samples contained interlamellar pores that were primarily oriented parallel to the substrate and intralamellar cracks which were mostly perpendicular to the substrate.

\subsection{Thermal Conductivity Results}

As an initial evaluation of thermal barrier performance, the thermal conductivity $\left(k_{\mathrm{th}}\right)$ of 2,8 , and $11 \mathrm{~N}$ coating samples were measured. Figure 6 shows temperature-dependent thermal conductivity results from representative SPS samples tested in the AS condition, and after being heat treated (HT) via a box furnace in air for $50 \mathrm{~h}$ at $1200{ }^{\circ} \mathrm{C}$ to simulate TBC service in a gas turbine. For comparison, corresponding data replotted from Ref 7 and 10 on APS and EB-PVD samples, respectively, is also included in Fig. 6. 

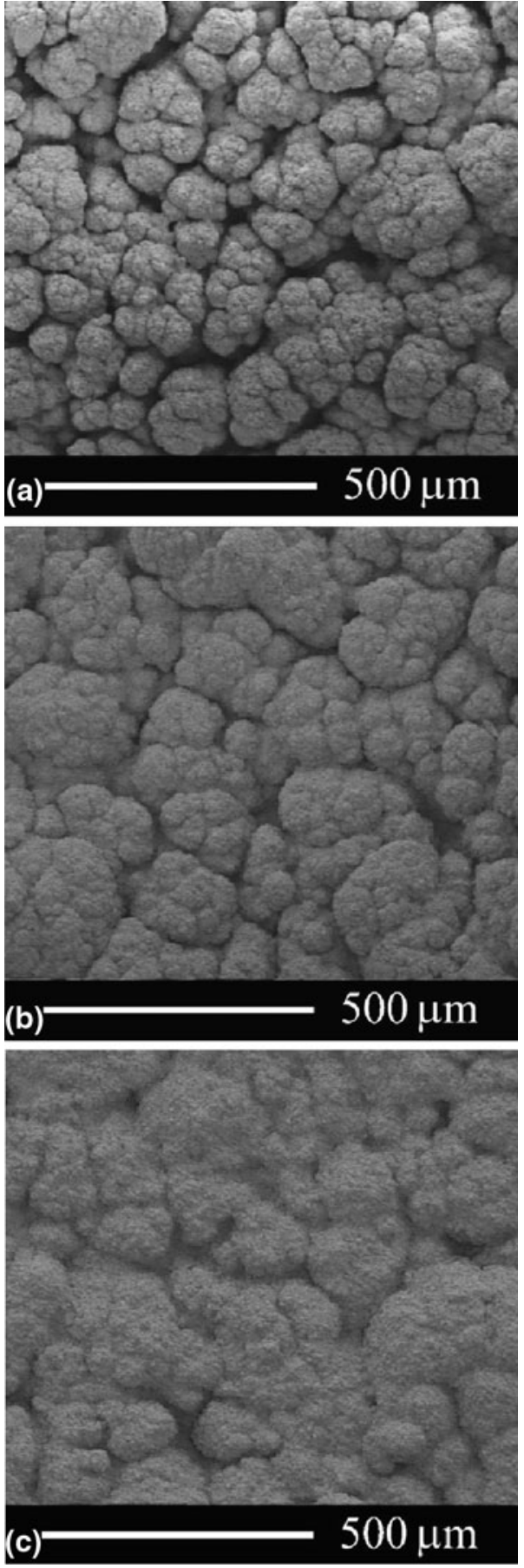

Fig. 3 SEM images showing the top surfaces on (a) $2 \mathrm{~N}$, (b) $8 \mathrm{~N}$, and (c) $11 \mathrm{~N}$ coatings

These data show that, in the AS condition, ranking the coating types from lowest to highest $k_{\text {th }}$ gives APS, $11 \mathrm{~N}$, EB-PVD, $2 \mathrm{~N}$, and $8 \mathrm{~N}$, with the $11 \mathrm{~N}$ and EB-PVD types being basically equivalent. All heat treatment $k_{\mathrm{th}}$ data exhibited an increase over the corresponding AS values. The $2 \mathrm{~N}, 11 \mathrm{~N}$, and EB-PVD values increased by approximately $0.2 \mathrm{~W} / \mathrm{m} / \mathrm{K}$, while the APS $k_{\text {th }}$ measurements went up on average by $1 \mathrm{~W} / \mathrm{m} / \mathrm{K}$.
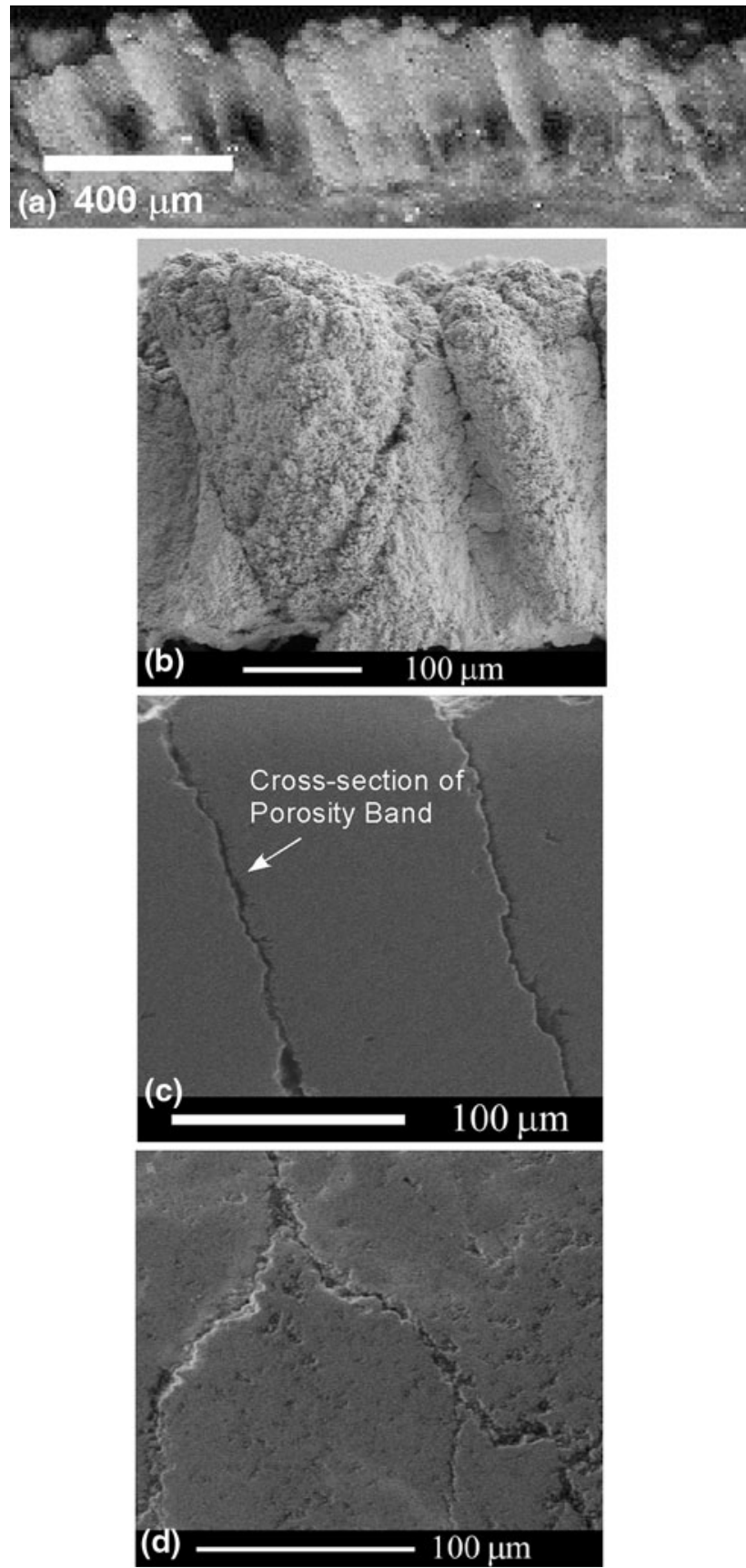

Fig. 4 (a) Optical cross-sectional micrograph of a $2 \mathrm{~N}$ coating showing columns. Cross-sectional SEM images showing the (b) columnar structures in a fractured $2 \mathrm{~N}$ cross section, (c) porosity bands in a polished $8 \mathrm{~N}$ cross section, and (d) porosity bands in a polished $11 \mathrm{~N}$ cross section

\section{Discussion}

\subsection{Microstructural Development}

While the columnar and cauliflower 2, 8, and $11 \mathrm{~N}$ microstructural features are not typical of spray-deposited coatings, some SPS studies (Ref 14, 20, 35) have reported these structures. In addition, similar features have been 


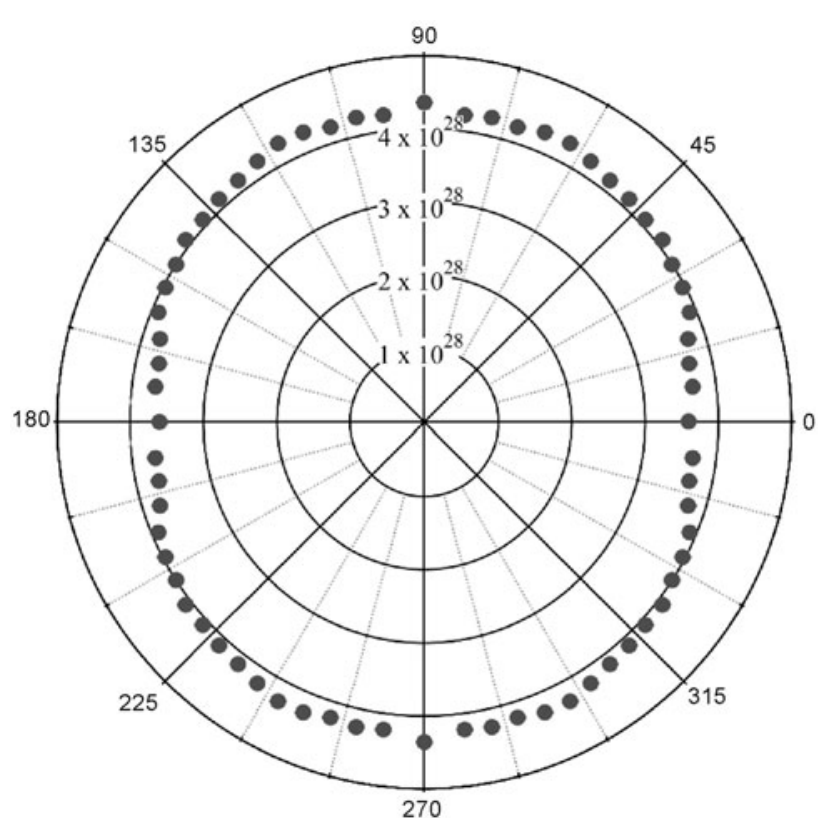

Fig. 5 A plot showing the azimuthal dependence of the Porod constants (units of $\mathrm{cm}^{-5}$ ) calculated from the SAXS of a beam perpendicular to the spray direction in an as-sprayed $8 \mathrm{~N}$ coating. The Porod shape describes the apparent distribution of the void specific surface area in a plane perpendicular to the substrate. The $0^{\circ} / 180^{\circ}$ axis in the above image is parallel to the substrate

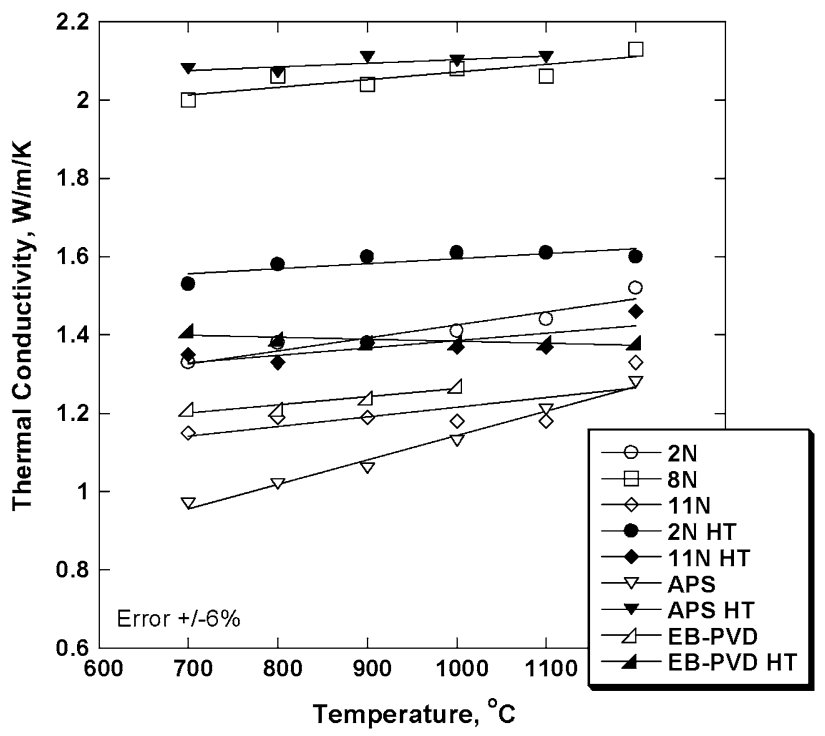

Fig. 6 Thermal conductivity vs. temperature data for as-sprayed (open points) and heat-treated (filled points) samples from 2, 8 , $11 \mathrm{~N}$, APS, and EBPVD coatings. The APS and SPS HT data are from samples heated for $50 \mathrm{~h}$ at $1200^{\circ} \mathrm{C}$; EBPVD HT data are from a sample heated for $100 \mathrm{~h}$ at $1100{ }^{\circ} \mathrm{C} .2 \mathrm{~N}$ data are replotted from Ref 28; APS data are replotted from Ref 10, and EBPVD data are replotted from Ref 7

observed previously in coatings generated by other spray or spray-like processes. Kanouff et al. found isolated columnar deposits on a grit-blasted aluminum plate substrate used in a high velocity oxy-fuel spray experiment for which the spray direction was $\sim 39^{\circ}$ from the substrate normal (Ref 36). The columns were separated from where the spray plume contacted the plate and were attributed to satellite droplets generated during the impact of the primary droplets on the substrate (Ref 36). Kanouff et al. proposed that the spray gases flowing along the plate surface carried the smaller satellite droplets downstream of the main deposition region and deposited them on surface asperities. As the deposition occurred preferentially on the side of the asperity facing the main deposition region, the deposits grew as columns into the gas flow transporting the satellite droplets. Hass et al. used the electron-beam directed vapor deposition (EB-DVD) process to produce cauliflower-like top surfaces on YSZ coatings (Ref 8 ). In these experiments, the angle between the vapor jet and the substrate surface was oscillated between $135^{\circ}$ and $-135^{\circ}$, causing most vapor to move along directions off the substrate normal prior to condensation (Ref 8). Findings like those published in Ref 8 and 36 suggest that the unique characteristics of the 2, 8, and $11 \mathrm{~N}$ microstructures resulted from the deposition of YSZ droplets having a significant velocity component parallel to the substrate.

For a spray deposition process, decreasing the particle, and hence, the droplet size in the gas/plasma plume increases the sensitivity of these bodies to changes in gas/ plasma velocity. In this study, the plasma flow was directed normal to the substrate. As a result, near the coating/ substrate the impinging plasma turned and moved across this surface. This change in the plasma flow exerted drag forces on the YSZ that tended to slow the droplet velocity component perpendicular to the substrate and increase the velocity component parallel to the substrate. Using numerical modeling, Oberste Berghaus et al. calculated the effects these forces have on various sizes of zirconia particles initially traveling at $400 \mathrm{~m} / \mathrm{s}$ perpendicular to the substrate and within a plasma flow of equal speed and direction (Ref 16). These particle velocities are consistent with droplet velocities measured at $5 \mathrm{~cm}$ from the gun face during SPS experimentation without a substrate (Ref 16). The results of the model, which have been replotted in Fig. 7 , show that the inertia of a $40-\mu \mathrm{m}$ diameter zirconia particle traveling at $400 \mathrm{~m} / \mathrm{s}$ is large enough to be unaffected by drag from the impinging plasma; however, these drag forces were determined to affect the trajectories of $400 \mathrm{~m} / \mathrm{s}$ zirconia particles with diameters between 1 and $5 \mu \mathrm{m}$ (Ref 16).

Using SEM micrographs like Fig. 2(b) and (d), the average lamella thickness for all the nanopowder SPS coatings was measured to be $300 \pm 30 \mathrm{~nm}$, where the interval width captures the central $95 \%$ of a $t$-distribution describing the lamella thicknesses. The average lamella diameter in $8 \mathrm{~N}$ coatings was estimated from a series of micrographs like Fig. 2(a). An examination of this representative figure shows that the longest dimension visible for the majority of lamellae is $<3.0 \mu \mathrm{m}$. Consequently, $3.0 \mu \mathrm{m}$ was used as the average lamella diameter to estimate conservatively the size of the YSZ droplets deposited while spraying an $8 \mathrm{wt} . \%$ nanopowder suspension. From the above dimensions, the lamellae were formed by 


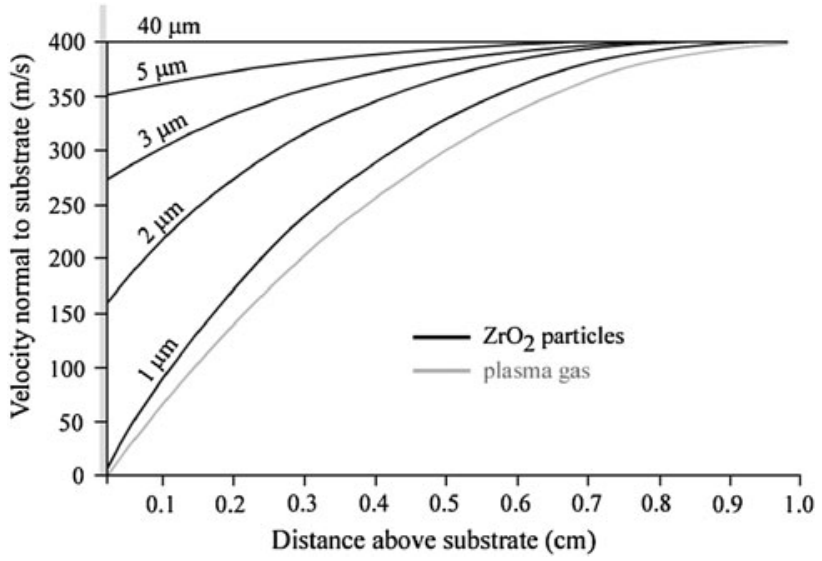

Fig. 7 Numerical simulation results replotted from Ref 16 showing how the changes in plasma velocity stemming from substrate impingement and the resulting drag influence the substrate normal velocity component of different diameters of zirconia particles within the plasma

YSZ droplets with diameters $<2 \mu \mathrm{m}$. Therefore, comparing the droplet size to the results in Fig. 7 suggests that drag forces from the impinging plasma caused the flight paths of all the YSZ droplets in the $8 \mathrm{~N}$ experiments to deviate from the spray direction. Conversely, the plasma impingement should have produced little change in the paths of droplets resulting from the $15-\mu \mathrm{m}$ diameter powder.

The impact trajectory predictions above led to the idea that the 2,8, and $11 \mathrm{~N}$ microstructural features, which are unique from common spray-deposited coatings, result from directional changes in droplet travel near the substrate. A similar hypothesis was also suggested by other researchers that found substrate roughness and size influenced the microstructures of coatings produced during SPS with nanosized powders (Ref 35$)$. To develop this premise further, theories were formulated defining deposition mechanisms leading to the three different microstructure types, i.e., those apparent in the $2 \mathrm{~N} / 8 \mathrm{~N}, 11 \mathrm{~N}$, and $8 \mathrm{M}$ coatings, observed in this study. For these theories, the YSZ droplet velocity is $400 \mathrm{~m} / \mathrm{s}$ perpendicular to the substrate surface prior to any impingement effects, and the substrate asperity heights are assumed to be significantly larger than the impacting droplet diameters. The hypothetical deposition mechanisms outlined below may change for conditions other than those assumed here.

4.1.1 Type 1 Spray Deposition Microstructure Development. Microstructures like those of the 2 and $8 \mathrm{~N}$ coatings (as revealed in Fig. 3a and b, and Fig. 4a-c) are proposed to form by a mechanism which will be referred to as type 1 spray deposition (1SD). In 1SD, YSZ droplets move with the plasma through the initial turn at substrate impingement. As a result, the substrate parallel velocity component of these droplets dominates the substrate normal component. However, as the plasma flows across the substrate, the inertia difference between the plasma and small YSZ droplets cause some of the entrained droplets to be unable to follow the more sudden directional changes produced as the plasma moves around surface asperities.

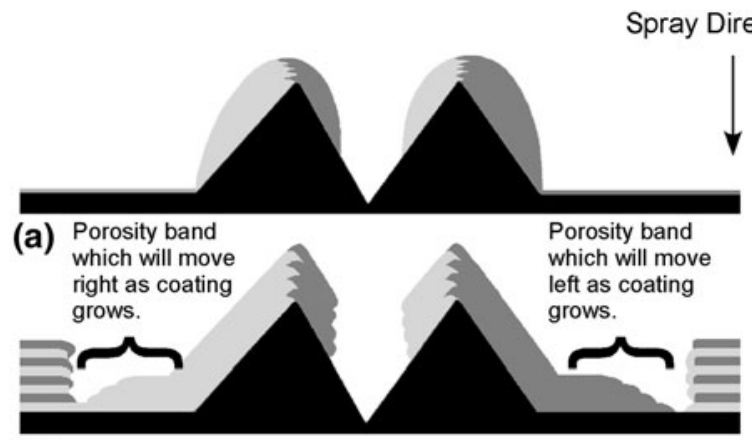

(b)

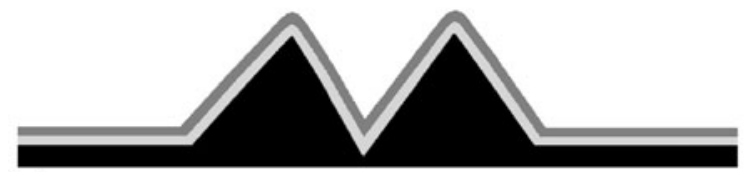

(c)

Fig. 8 Schematics illustrating the deposition characteristics occurring on and away from substrate surface asperities during (a) $1 \mathrm{SD}$, (b) $2 \mathrm{SD}$, and (c) 3SD. The spray direction is the same in each figure. The black regions denote the substrate. The light gray regions represent material deposited by droplets having a substrate parallel velocity component directed from left to right, and the dark gray regions represent material deposited by droplets having a substrate parallel velocity component directed from right to left

Consequently, 1SD results almost exclusively in droplet impacts on the sides of surface asperities, as shown in Fig. 8(a). Initially, deposits formed on substrate asperities grow both laterally and vertically. During this time, the lateral growth of taller deposits may engulf shorter deposits. Among the remaining deposits of similar heights, the increase in drag forces generated by the decrease in spacing separating these structures reduces the plasma flowing between them. This process eventually causes the lateral growth to stop, leaving an interdeposit gap. As spraying proceeds, the ongoing vertical growth of the deposits and interdeposit gaps produces columnar structures that span the coating cross section normal to the substrate.

Spraying will naturally yield localized nonuniform distributions of droplet impacts, which can lead to asperities in the coating surface. These coating asperities can become sites of preferential 1SD. Consequently, the coating is expected to have a surface featuring multiple deposits separated by valleys; these deposits are the cluster formations comprising the cauliflower-like surface structures mentioned previously.

4.1.2 Type 2 Spray Deposition Microstructure Development. Type 2 spray deposition (2SD) is proposed as describing conditions in which the droplet retains a velocity directed primarily perpendicular to the substrate, yet the substrate parallel component still affects deposition. In this case, the droplets are more massive than those depositing according to the 1SD mechanism, and they separate from the plasma before completing the substrate impingement turn. Consequently, deposition in regions between surface asperities increases with 2SD. However, 
the effects of the impinging plasma drag cause the droplets to follow trajectories that result in surface asperities shadowing portions of the substrate downstream from the asperity, which is illustrated in Fig. 8(b). Early in the coating process, the shadowing occurring with 2SD will create variations in the growth rate. Figure 8(b) shows the thickness of the coating deposited in the unshadowed regions at the left and right extremes of the figure to be growing twice as fast as that on the substrate asperities. This difference is because the left substrate asperity blocks the oblique droplet trajectories from reaching two regions-identified by an absence of light gray bands on Fig. 8(b) - of the substrate to the right of the peak on this asperity. Likewise, the right substrate asperity blocks droplets from reaching two regions-identified by an absence of dark gray bands on Fig. 8(b) — of the substrate to the left of the peak on this asperity. As the height differential between the coating in the unshadowed regions and the material deposited on top of the substrate asperities decreases, the deposition on the side of the former will increase. This increase causes the unshadowed sections of the coating to grow toward that covering the substrate asperities. Therefore, given a long enough spray time, the coating building from the initially unshadowed sections will overgrow that above the substrate asperities. Due to this overgrowth behavior, a coating microstructure formed by $2 \mathrm{SD}$ should exhibit a convergence of the porosity bands separating columnar structures like that observed in the $11 \mathrm{~N}$ coatings and shown in Fig. 4(d).

As with 1SD, the droplet trajectories in the 2SD mechanism promote cluster formations on coating surface asperities. However, these structures exhibit less growth with 2SD than with 1SD because droplets with velocities mainly normal to the surface are less likely to deposit preferentially on surface asperities. Therefore, cluster formations will be less distinct on the surface of a microstructure produced by $2 \mathrm{SD}$ than by $1 \mathrm{SD}$.

4.1.3 Type 3 Spray Deposition Microstructure Development. Type 3 spray deposition (3SD) is proposed as describing conditions in which plasma drag forces do not affect the deposition characteristics, meaning the droplets yielding 3SD are more massive than those causing 2SD. As a result, 3SD is characterized by deposition on the entire substrate surface (Fig. 8c) during each plasma gun pass, i.e., droplets do not preferentially impact on surface asperities, and no shadowing occurs from these asperities. The droplet trajectories required for this complete coverage would be approximately normal to the substrate surface. Thus, Fig. 7 suggests that 3SD would occur when plasma spraying with YSZ droplets having diameters larger than $5 \mu \mathrm{m}$.

The complete substrate coverage possible with 3SD prevents the formation of columnar structures separated by porosity bands (Fig. 8c). In addition, the momentum of the droplets in this mechanism should preferentially drive liquid into the valleys in the coating/substrate surface. Thus, coating asperities generated by nonuniform 3SD will not grow into cluster formations; instead, the coating surface will tend to become more planar than the gritblasted substrate surface. This type of deposition produces the stereotypical APS coating microstructure.

\subsection{SAXS Analysis with Respect to Deposition Conditions}

As shown in Fig. 1(b), an interlamellar pore has an orientation similar to the YSZ lamella formed by the droplet which created the pore. Therefore, knowledge of the orientation of the interlamellar pores obtained from small angle scattering experiments can be used to approximate the lamellae orientations within a coating. These experimental results will also include scattering from intralamellar cracks, but, since these cracks tend to run perpendicular to interlamellar pores, the scattering from these two void types will be orthogonal. In addition, based on SEM observations, intralamellar cracks are likely to constitute less of the total void surface area than interlamellar pores in nanopowder SPS coatings. Figure 1(b) shows that plasma-sprayed microstructures also contain spherical, intralamellar pores. However, the contribution from this type of pore can be neglected because their surface area is small relative to that of intralamellar cracks and interlamellar pores (Ref 5).

The azimuthal dependence of the Porod constants calculated using SAXS intensities produced by 2 and $8 \mathrm{~N}$ samples were near circular shapes (Fig. 5) (Ref 28). However, SEM images like Fig. 2(b) confirmed that the interlamellar pores in the 2 and $8 \mathrm{~N}$ coatings had oblate or lamellar shapes. Therefore, the most probable explanation for the isotropy of apparent void SSA in these SPS coatings is a near random orientation of the lamellae relative to the substrate plane. Such an orientation is expected for coatings generated by 1SD because the droplet impacts in this deposition mechanism result from the plasma flowing around and over surface asperities. Consequently, the planes describing droplet spreading should form a range of angles with the substrate plane.

SANS results correlated to the $8 \mathrm{M}$ coatings suggest these coatings were composed primarily of lamellae with radial axes approximately parallel to the spray direction. Such a microstructure is consistent with 3SD. This mechanism tends to generate planar coatings, which increases the probability of an impacting droplet spreading parallel to the substrate plane.

SAXS experiments were not performed on $11 \mathrm{~N}$ samples. Based on the earlier deposition theory, the void SSA orientation in the $11 \mathrm{~N}$ coatings could be more anisotropic than those of the 2 or $8 \mathrm{~N}$ samples, with a greater SSA percentage orientated roughly parallel to the substrate plane. However, the cauliflower-like surface features and the $k_{\text {th }}$ increase with heat treatment (discussed below) suggest the azimuthal dependence of Porod constants determined from the SAXS generated by $11 \mathrm{~N}$ microstructures would be nearly isotropic.

\subsection{Thermal Conductivity Discussion with Regard to $1 S D, 2 S D$, and $3 S D$ Microstructures}

As the maximum temperature during the laser flash testing was $1200{ }^{\circ} \mathrm{C}$, the heat transfer occurred primarily by phonon transport in the YSZ (Ref 22). Voids within the microstructure inhibit this transport in two ways. First, because phonons must move around voids, these features

. 
Table 3 Bulk density and total porosity values for the SPS thermal conductivity test specimens

\begin{tabular}{lcc}
\hline Coating ID & Bulk density, $\mathbf{g} / \mathbf{c m}^{\mathbf{3}}$ & Total porosity, vol. $\%$ \\
\hline $2 \mathrm{~N}$ & $3.92 \pm 0.06$ & $37 \pm 2$ \\
$2 \mathrm{~N}-\mathrm{HT}$ & $4.20 \pm 0.08$ & $31 \pm 2$ \\
$8 \mathrm{~N}$ & $5.19 \pm 0.06$ & $14 \pm 1$ \\
$11 \mathrm{~N}$ & $4.50 \pm 0.04$ & $26 \pm 1$ \\
$11 \mathrm{~N}-H T$ & $4.56 \pm 0.03$ & $25 \pm 1$
\end{tabular}

Each uncertainty interval captures the central $95 \%$ of a $t$-distribution describing the sample data

increase the average transport distance, and, second, by constricting the cross-sectional area available for transport, voids increase phonon-phonon scattering interactions (Ref 23). As stated in Section 2.2, the macroscopic heat flux through the test samples was one-dimensional and parallel to the coating spray direction. Therefore, both the amount and distribution of porosity within a microstructure affected the sample thermal conductivity (Ref 37).

A comparison of the density and porosity values in Table 3 and the discussion of porosity orientation in the preceding section lead to the conclusion that the $k_{\text {th }}$ data of the $2 \mathrm{~N}$ coatings was lower than that of the $8 \mathrm{~N}$ coatings because the former contained more porosity. Conversely, the $11 \mathrm{~N}$ sample contained less porosity than the $2 \mathrm{~N}$ sample, yet the $11 \mathrm{~N}$ porosity distribution caused this specimen to have lower $k_{\text {th }}$ values. The $11 \mathrm{~N}$ microstructures were the only ones observed to contain porosity bands that interconnect, which creates more conduction pathway restrictions than the linear $2 \mathrm{~N} / 8 \mathrm{~N}$ bands. Since the porosity bands are significantly larger than intralamellar cracks or interlamellar pores, it is not surprising that the $11 \mathrm{~N}$ porosity was more effective at reducing heat conduction than that of the $2 \mathrm{~N}$ specimen.

The increase in coating thermal conductivity data following heat treatments at 1100 and $1200{ }^{\circ} \mathrm{C}$ suggest microstructural void changes occurred during heating. At these temperatures a YSZ microstructure will undergo sintering, resulting in crack closure and pore spherodization (Ref $5,10,38,39)$. These processes resulted in a $30 \%$ decrease in the total apparent void SSA observed between the AS and heat treated 2 and $8 \mathrm{~N}$ SAXS samples (Ref 29). Similarly, Petorak (Ref 32) reports the total apparent void SSA in APS YSZ coatings decreased by $16 \%$ after $3 \mathrm{~h}$ at $1200{ }^{\circ} \mathrm{C}$. Following $100 \mathrm{~h}$ at $1100{ }^{\circ} \mathrm{C}$, the SSA of the open and closed porosity in the EB-PVD YSZ coatings of (Ref 40 ) each decreased by $68 \%$. Although each coating type exhibited a void SSA reduction, the corresponding average $k_{\text {th }}$ increases do not correlate linearly with the SSA changes. As shown in Fig. 6 , the $k_{\text {th }}$ values for the $2 \mathrm{~N}$ and EB-PVD samples increase an average of $0.2 \mathrm{~W} / \mathrm{m} / \mathrm{K}$ between the AS and HT measurements, while Ref 32 reports a $0.54 \mathrm{~W} / \mathrm{m} / \mathrm{K}$ average $k_{\text {th }}$ increase after heating APS YSZ samples for $3 \mathrm{~h}$ at $1200{ }^{\circ} \mathrm{C}$.

The disparity in the sensitivity of coating thermal conductivity to heat treatment between EB-PVD and
APS YSZ samples can be attributed to the influence of void structure on this property. In the as-deposited condition, the columnar grains forming an EB-PVD YSZ coating contain rows of isolated pores which are submicron in size and separation (Ref 7). Sintering of these coatings causes pore spheriodization, during which some pores grow at the expense of others (Ref 7). However, even after $100 \mathrm{~h}$ at $1100{ }^{\circ} \mathrm{C}$, the EB-PVD YSZ void structure still consists of isolated pores that are submicron in size and separation (Ref 7). On the other hand, the intralamellar cracks in an AS APS YSZ coating can link interlamellar pores to produce void networks (Ref 31, 38). The destruction of these networks via crack closure during sintering can leave isolated interlamellar pores separated by millimeter-sized gaps, significantly raising the coating $k_{\mathrm{th}}(\operatorname{Ref} 32,38)$. In fact, the results of Ref 10 and 32 show that roughly half of the $k_{\mathrm{th}}$ increase for APS YSZ coatings after a 3-50 h, $1200{ }^{\circ} \mathrm{C}$ heat treatment can be attributed to crack closure. As for the relative $k_{\text {th }}$ increases associated with pore spheroidization, APS YSZ interlamellar porosity tends be oriented more normal to the spray direction than the intracolumnar porosity is to the EB-PVD column growth direction (Ref 6, 7, 31, 32, 38). Consequently, when the macroscopic heat flow direction is parallel to the APS coating spray direction and the EB-PVD column growth direction, pore spheriodization will have a greater effect on the $k_{\text {th }}$ of the former coating type.

The void structure of the nanopowder SPS coatings in this work was more typical of an EB-PVD YSZ coating than an APS YSZ coating. The extent of intralamellar cracking present in micrographs of these SPS coatings suggests crack-pore void networks were rare, meaning the interlamellar pores were mainly isolated like intracolumnar EB-PVD pores. In addition, the SAXS results indicate the majority of intralamellar pore SSA to be aligned along directions that cannot be considered roughly perpendicular to the spray direction. As a result of the similarities, the $k_{\text {th }}$ increase seen in Fig. 6 between the AS and HT SPS samples shows a better agreement with the corresponding change in the EB-PVD data than that for the APS data.

\section{Summary}

The SPS process was employed to produce coatings from suspensions containing $15 \mu \mathrm{m}$ and $80-\mathrm{nm}$ diameter YSZ powders. Suspensions containing $8 \mathrm{wt} . \%$ of $15 \mu \mathrm{m}$ powder $(8 \mathrm{M})$ resulted in the well-known spray deposition microstructure-overlapping lamellae primarily oriented parallel to the substrate. Conversely, the $80 \mathrm{~nm}$ powder suspensions yielded unique microstructures in which lamellae formed columnar structures topped with cauliflower-like formations. When spraying suspensions containing $2 \mathrm{wt} \%(2 \mathrm{~N})$ or $8 \mathrm{wt} . \%(8 \mathrm{~N})$ nanopowder, the columns were composed of an approximately random orientation of lamellae and were separated by linear porosity bands. With an $11 \mathrm{wt} \%$ (11 N) powder suspension, interconnected porosity bands were observed. 
Hypotheses on the formation mechanisms producing these coatings were developed from microstructural observations and predictions of droplet flight paths. This information suggests that the change in relative influences of drag and inertial forces with YSZ droplet size can result in three types of spray deposition. For 1SD, the plasma drag forces during substrate impingement dominate the droplet inertia and redirect the droplet velocity from normal to along to the substrate surface. Consequently, droplets impact preferentially on asperities, generating deposits that grow to become columnar structures separated by linear porosity bands. The $1 \mathrm{SD}$ microstructure is analogous to that of the 2 and $8 \mathrm{~N}$ coatings from this study. With $2 \mathrm{SD}$, the droplet velocity remains mostly normal to the substrate surface, but the impinging plasma drag influences the droplet trajectories such that surface asperities block deposition in downstream regions and create porosity bands. The coating growth rate differences between the resulting shadowed and unshadowed regions cause faster growing deposits to overgrow slower ones, producing a convergence of porosity bands like what was observed in the $11 \mathrm{~N}$ coatings. In 3SD, the coating microstructure exhibits no signs of droplets being influenced by drag from the plasma impingement. These droplets follow a path with a substrate normal component larger enough to prevent any preferential deposition on surface asperities or asperity shadowing. Thus, like the $8 \mathrm{M}$ coatings, 3SD microstructures do not contain columnar structures or porosity bands, and the lamellae tend to be oriented parallel to the substrate.

The thermal diffusivities of $80 \mathrm{~nm}$ powder SPS coatings were measured in as-sprayed and heat-treated conditions, and the data were used to calculate coating thermal conductivities. Over the temperature range from 700 to $1200{ }^{\circ} \mathrm{C}$, the average thermal conductivities of 2 and $11 \mathrm{~N}$ samples were, respectively, 1.4 and $1.2 \mathrm{~W} / \mathrm{m} / \mathrm{K}$ in the AS condition and 1.6 and $1.4 \mathrm{~W} / \mathrm{m} / \mathrm{K}$ after $50 \mathrm{~h}$ at $1200{ }^{\circ} \mathrm{C}$. The $k_{\text {th }}$ increases for these SPS samples were less than one-third of those for APS YSZ coatings tested under the same conditions (Ref 10,32). The decreased change in the SPS samples $k_{\text {th }}$ after heat treatment was attributed to randomly oriented and isolated interlamellar pores, implying the 2 and $11 \mathrm{~N}$ coatings had void structure characteristics similar to an EB-PVD coating.

\section{Acknowledgments}

Major portions of this research were funded by the National Science Foundation via grant CMMI-0456534. Ames Laboratory is operated for the U.S. Department of Energy by Iowa State University under Contract No. DEAC02-07CH11358. Use of the Advanced Photon Source at Argonne National Laboratory was supported by the U.S. Department of Energy, Office of Science, Office of Basic Energy Sciences, under Contract No. DE-AC0206CH11357. This project involved research sponsored by the Assistant Secretary for Energy Efficiency and Renewable Energy, Office of FreedomCAR and Vehicle Technologies, as part of the High Temperature Materials
Laboratory User Program, Oak Ridge National Laboratory, managed by UT-Battelle, LLC, for the U.S. Department of Energy under contract number DE-AC0500OR22725.

\section{References}

1. R.A. Miller, Thermal Barrier Coatings for Aircraft Engines: History and Directions, J. Therm. Spray Technol., 1997, 6(1), p 35-42

2. U. Schulz, C. Leyens, K. Fritscher, M. Peters, B. Saruhan-Brings, O. Lavigne, J.-M. Dorvaux, M. Poulain, R. Mévrel, and M. Caliez, Some Recent Trends in Research and Technology of Advanced Thermal Barrier Coatings, Aerosp. Sci. Technol., 2003, 7, p 73-80

3. P. Fauchais, Understanding Plasma Spraying, J. Phys. D Appl. Phys., 2004, 37, p R86-R108

4. R. McPherson, A Review of Microstructure and Properties of Plasma Sprayed Ceramic Coatings, Surf. Coat. Technol., 1989, 39(40), p 173-181

5. J. Ilavsky, G.G. Long, A.J. Allen, and C.C. Berndt, Evolution of the Void Structure in Plasma-Sprayed YSZ Deposits During Heating, Mater. Sci. Eng. A, 1999, 272, p 215-221

6. A. Kulkarni, A. Goland, H. Hermana, A.J. Allen, T. Dobbins, F. DeCarlo, J. Ilavsky, G.G. Long, S. Fang, and P. Lawton, Advanced Neutron and X-ray Techniques for Insights into the Microstructure of EB-PVD Thermal Barrier Coatings, Mater. Sci. Eng. A, 2006, 426, p 43-52

7. F. Renteria, B. Saruhan, U. Schulz, H.-J. Raetzer-Scheibe, J. Haug, and A. Wiedenmann, Effect of Morphology on Thermal Conductivity of EB-PVD PYSZ TBCs, Surf. Coat. Technol., 2006, 201, p 2611-2620

8. D.D. Hass, A.J. Slifka, and H.N.G. Wadley, Low Thermal Conductivity Vapor Deposited Zirconia Microstructures, Acta Mater., 2001, 49, p 973-983

9. H. Zhao, F. Yu, T.D. Bennett, and H.N.G. Wadley, Morphology and Thermal Conductivity of Yttria-Stabilized Zirconia Coatings, Acta Mater., 2006, 54, p 5195-5207

10. R.W. Trice, Y.J. Su, J.R. Mawdsley, K.T. Faber, A.R. De Arellano-Lopez, H. Wang, and W.D. Porter, Effect of Heat Treatment on Phase Stability, Microstructure, and Thermal Conductivity of Plasma-Sprayed YSZ, J. Mater. Sci., 2002, 37, p 2359-2365

11. P. Fauchais, M. Fukumoto, A. Vardelle, and M. Vardelle, Knowledge Concerning Splat Formation: An Invited Review, J. Therm. Spray Technol., 2004, 13, p 337-360

12. A. Kulkarni, A. Vaidya, A. Goland, S. Sampath, and H. Herman, Processing Effects on Porosity-Property Correlations in Plasma Sprayed Yttria-Stabilized Zirconia Coatings, Mater. Eng. A, 2003, 359, $\mathrm{p}$ 100-111

13. Z. Chen, R.W. Trice, M. Besser, X. Yang, and D. Sordelet, AirPlasma Spraying Colloidal Solutions of Nanosized Ceramic Powders, J. Mater. Sci., 2004, 39, p 4171-4178

14. R. Siegert, "A Novel Process for the Liquid Feedstock Plasma Spray of Ceramic Coatings with Nanostructural Features," Doctoral Thesis, Institut fur Werkstoffe und Verfahren der Energietechnik, 2005

15. J. Fazilleau, C. Delbos, V. Rat, J.F. Coudert, P. Fauchais, and B. Pateyron, Phenomena Involved in Suspension Plasma Spraying Part 1: Suspension Injection and Behavior, Plasma Chem. Plasma Process., 2006, 26, p 371-391

16. J. Oberste Berghaus, S. Bouaricha, J.-G. Legoux, and C. Moreau, Injection Conditions and In-Flight Particle States in Suspension Plasma Spraying of Alumina and Zirconia Nano-Ceramics, Proceedings of the International Thermal Spray Conference, C. Berndt and E. Lugsheider, Ed., May 2-4, 2005 (Basel, Switzerland), ASM International, 2005

17. C. Delbos, J. Fazilleau, V. Rat, J.F. Coudert, P. Fauchais, and L. Bianchi, Influence of Powder Size Distribution and Heat Flux on Yttria Stabilised Coatings Elaborated by Liquid Suspension 
Injection in a DC Plasma Jet, Proceedings of the International Thermal Spray Conference, C. Berndt and E. Lugsheider, Ed., May 2-4, 2005 (Basel, Switzerland), ASM International, 2005

18. J. Oberste Berghaus, S. Bouaricha, J.-G. Legoux, C. Moreau, and T. Chraska, Suspension Plasma Spraying of Nano-Cermics Using an Axial Injection Torch, Proceedings of the International Thermal Spray Conference, C. Berndt and E. Lugsheider, Ed., May 24, 2005 (Basel, Switzerland), ASM International, 2005

19. R. Siegert, J.-E. Doring, J.-L. Marques, R. Vassen, D. Sebold, and D. Stover, Influence of the Injection Parameters on the Suspension Plasma Spraying Coating Properties, Proceedings of the International Thermal Spray Conference, C. Berndt and E. Lugsheider, Ed., May 2-4, 2005 (Basel, Switzerland), ASM International, 2005

20. C. Delbos, J. Fazilleau, V. Rat, J.F. Coudert, P. Fauchais, and B. Pateyron, Phenomena Involved in Suspension Plasma Spraying, Part 2: Zirconia Particle Treatment and Coating Formation, Plasma Chem. Plasma Process., 2006, 26, p 393-414

21. W. Beele, G. Marijnissen, and A. van Lieshout, The Evolution of Thermal Barrier Coatings-Status and Upcoming Solutions for Today's Key Issues, Surf. Coat. Technol., 1999, 120-121, p 61-67

22. J.R. Nicholls, K.J. Lawson, A. Johnstone, and D.S. Rickerby, Methods to Reduce the Thermal Conductivity of EB-PVD TBCs, Surf. Coat. Technol., 2002, 151-152, p 383-391

23. P.G. Klemens, Theory of Thermal Conduction in Thin Ceramic Films, Int. J. Thermophys., 2001, 22(1), p 265-275

24. Coulter ${ }^{\circledR}$ LS Series Product Manual, Coulter Corporation, Miami, FL 1994

25. A. Jillavenkatesa, S.J. Dapkunas, and L-S. H. Lum, NIST Special Publication 960-1: Particle Size Characterization, http:// www.msel.nist.gov/practiceguides/SP960_1.pdf, 2001

26. S. Raghavan, H. Wang, R.B. Dinwiddie, W.D. Porter, and M.J. Mayo, The Effect of Grain Size, Porosity and Yttria Content on the Thermal Conductivity of Nanocrystalline Zirconia, Scr. Mater., 1998, 39(8), p 1119-1125

27. J.R. Piascik, J.Y. Thompson, C.A. Bower, and B.R. Stoner, Evaluation of Crystallinity and Film Stress in Yttria-Stabilized Zirconia Thin Films, J. Vac. Sci. Technol., 2005, A23(5), p 1419-1424

28. K. VanEvery, M. Krane, R.W. Trice, W. Porter, H. Wang, M. Besser, D. Sordelet, J. Ilavsky, and J. Almer, In-Flight Alloying of Nanocrystalline Yttria-Stabilized Zirconia Using Suspension Spray to Produce Ultra-Low Thermal Conductivity Thermal Barriers, Int. J. Appl. Ceram. Technol. (in press)
29. K. VanEvery, "Development and Evaluation of Suspension Plasma Sprayed Yttria Stabilized Zirconia Coatings as Thermal Barriers," Doctoral Thesis, Purdue University, 2009

30. O. Glatter and O. Kratky, Small Angle X-ray Scattering, Academic Press, New York, 1982

31. J. Ilavsky, A.J. Allen, G.G. Long, S. Krueger, C.C. Berndt, and H. Herman, Influence of Spray Angle on the Pore and Crack Microstructure of Plasma-Sprayed Deposits, J. Am. Ceram. Soc., 1997, 80(3), p 733-742

32. C.A. Petorak, "Evolution of the Plasma-Sprayed Microstructure in $7 \mathrm{wt} \%$ Yttria-Stabilized Zirconia Thermal Barrier Coatings During Uniaxial Stress Relaxation and the Concomitant Changes in Material Properties," Doctoral Thesis, Purdue University, 2007

33. L. Pawlowski, Suspension and Solution Thermal Spray Coatings, Surf. Coat. Technol., 2009, 203, p 2807-2829

34. R.W. Trice, C. Batson, C. Scharff, and K.T. Faber, The Role of Starting Powder Size on the Compressive Response of StandAlone Plasma-Sprayed Alumina Coatings, J. Mater. Sci., 2002, 37, p 629-636

35. J. Oberste Berghaus, J.-G. Legoux, C. Moreau, F. Tarasi, and T. Chráska, Mechanical and Thermal Transport Properties of Suspension Thermal-Sprayed Alumina-Zirconia Composite Coatings, J. Therm. Spray Technol., 2008, 17(1), p 91-104

36. M.P. Kanouff, R.A. Neiser, Jr., and T.J. Roemer, Surface Roughness of Thermal Spray Coatings Made with Off-Normal Spray Angles, J. Therm. Spray Technol., 1998, 7(2), p 219-228

37. A. Bjorneklett, L. Haukeland, J. Wigren, and H. Kristiansen, Effective Medium Theory and the Thermal Conductivity of Plasma-Sprayed Ceramic Coatings, J. Mater. Sci., 1994, 29, p 4043-4050

38. A.J. Allen, J. Ilavsky, G.G. Long, J.S. Wallace, C.C. Berndt, and H. Herman, Microstructural Characterization of Yttria-Stabilized Zirconia Plasma-Sprayed Deposits Using Multiple Small-Angle Neutron Scattering, Acta Mater., 2001, 49, p 1661-1675

39. K.A. Erk, C. Deschaseaux, and R.W. Trice, Grain-Boundary Grooving of Plasma-Sprayed Yttria-Stabilized Zirconia Thermal Barrier Coatings, J. Am. Ceram. Soc., 2006, 89(5), p 16731678

40. A. Flores Renteria and B. Saruhan, Effect of Ageing on Microstructure Changes in EB-PVD Manufactured Standard PYSZ Top Coat of Thermal Barrier Coatings, J. Eur. Ceram. Soc., 2006, 26, p 2249-2255 